\section{omi}

OAK RIDGE

NATIONAL

LABORATORY

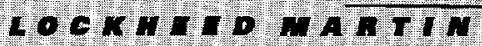
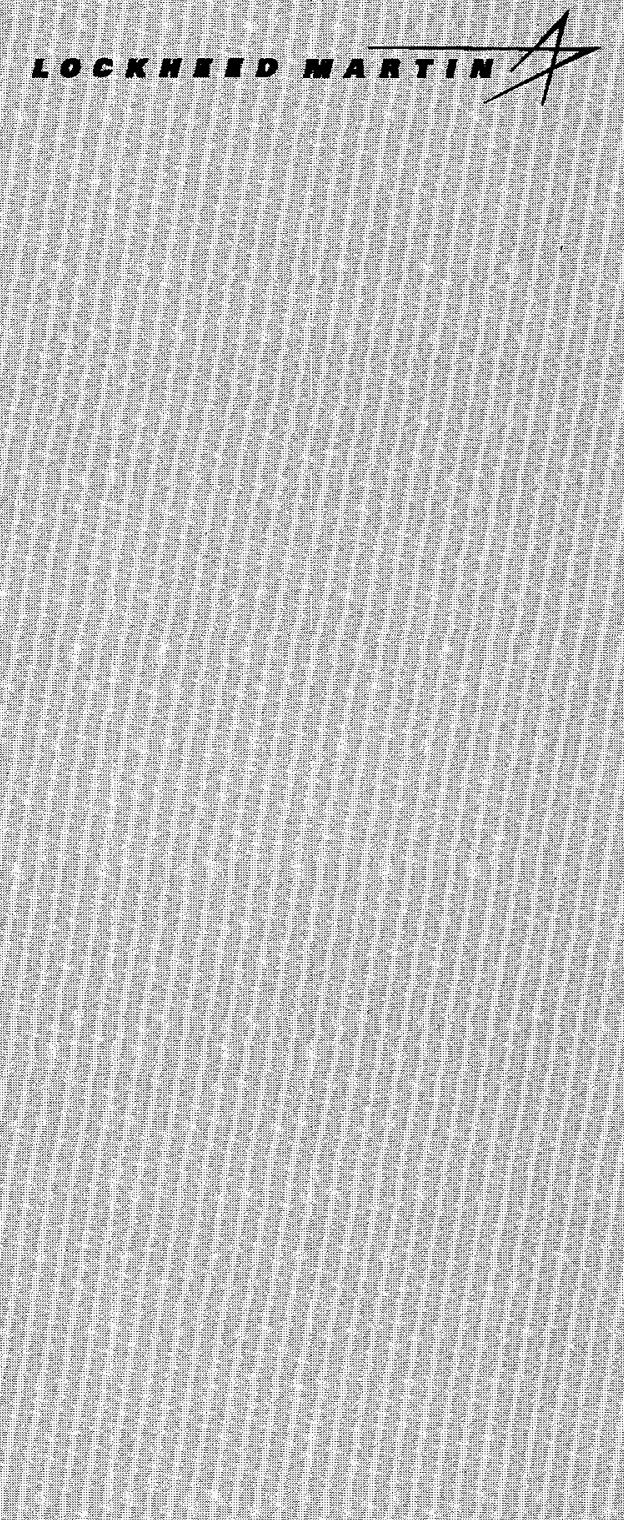

MANAGED BY

LOCKHEED MARTIN ENERGY SYSTEMS, INC.

FOR THE UNITED STATES

DEPARTMENT OF ENERGY

ORNLTM-13308

\section{Methods and Results for Stress Analyses on 14-Ton, Thin-Wall Depleted UF ${ }_{6}$ Cylinders}

\author{
J. R. Kirkpatrick \\ C. K. Chung \\ J. L. Frazier \\ D. K. Kelley
}

\section{OSTI}


This report has been reproduced directly from the best available copy.

Available to DOE and DOE contractors from the Office of Scientific and Technical

Information, P.O.Box 62, Oak Ridge, TN 37831; prices available from (423) 576-8401, FTS 626-8401.

Available to the public from the National Technical Information Service, U.S. Department

of Commerce, 5285 Port Royal Rd., Springfield, VA 22161

This report was prepared a an account of work sponsored by an agency of the United States Govemment. Neither the United States Govemment nor any agency thereof, nor any of their employees, makes any warranty, express or implied, or assumes any legal liability or responsibility for the accuracy. completeness, or usefulness of any information, apparatus, product, or process disclosed, or represents that its use would not infringe privately owned rights. Reference herein to any specific commercial product, process, or service by trade name, trademark, manufacturer, or otherwise, does nol necessarily constitute or imply its endorsement, recommendation, of favoring by the United States Government or any agency thereof. The view and opinions of authors expressed herein do not necessarily state or reflect those of the UnitedStatesGovernment or any agency thereof. 


\section{DISCLAIMER}

Portions of this document may be illegible electronic image products. Images are produced from the best available original document. 


\title{
METHODS AND RESULTS FOR STRESS ANALYSES ON 14-TON, THIN-WALL DEPLETED UF 6 CYLINDERS
}

\author{
J. R. Kirkpatrick \\ Computational Physics and Engineering Division, ORNL \\ C. K. Chung, J. L. Frazier, and D. K. Kelley \\ Environmental Management and Enrichment Facilities \\ Technical Support Organization
}

October 1996

\author{
Prepared by the \\ OAK RIDGE NATIONAL LABORATORY \\ Oak Ridge, Tennessee 37831 \\ managed by \\ LOCKHEED MARTIN ENERGY RESEARCH CORP. \\ for the \\ U.S. DEPARTMENT OF ENERGY \\ under contract DE-AC05-96OR22464
}


, 
CONTENTS

Page

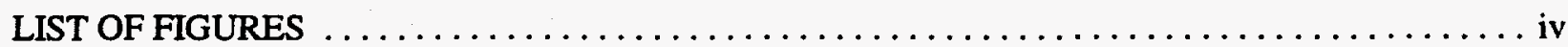

LIST OF TABLES $\ldots \ldots \ldots \ldots \ldots \ldots \ldots \ldots \ldots \ldots \ldots \ldots \ldots \ldots \ldots \ldots \ldots \ldots \ldots$

EXECUTIVE SUMMARY $\ldots \ldots \ldots \ldots \ldots \ldots \ldots \ldots \ldots \ldots \ldots \ldots \ldots \ldots \ldots \ldots \ldots \ldots \ldots \ldots \ldots \ldots$

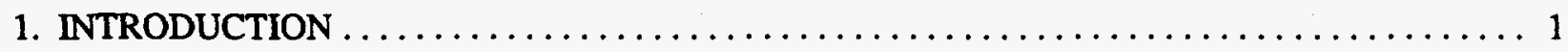

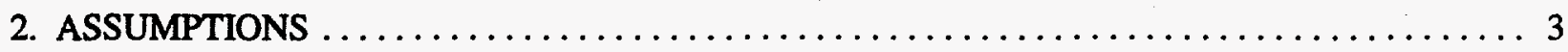

3. MODELING OF THE FINITE ELEMENT PROBLEMS $\ldots \ldots \ldots \ldots \ldots \ldots \ldots \ldots \ldots \ldots$

4. RESULTS FROM STRESS ANALYSES $\ldots \ldots \ldots \ldots \ldots \ldots \ldots \ldots \ldots \ldots \ldots \ldots$

4.1 LOCATION OF THE WOODEN SUPPORT CHOCKS VS MAXIMUM STRESS FOR SINGLE-TIER STORAGE CYLINDERS $\ldots \ldots \ldots \ldots \ldots \ldots \ldots \ldots \ldots \ldots \ldots \ldots \ldots \ldots 9$

4.2 MAXIMUM STRESS VS LOCATION OF THE STACKED CYLINDER $\ldots \ldots \ldots \ldots \ldots \ldots 12$

4.3 LIFTING OF BREACHED CYLINDERS $\ldots \ldots \ldots \ldots \ldots \ldots \ldots \ldots \ldots \ldots \ldots \ldots \ldots \ldots$

4.4 LIFTING OF CYLINDERS WITH SHELLS INTACT $\ldots \ldots \ldots \ldots \ldots \ldots \ldots \ldots \ldots \ldots \ldots$

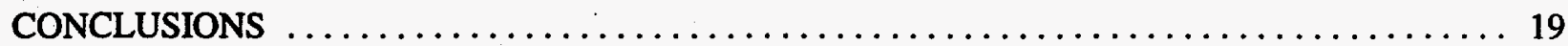

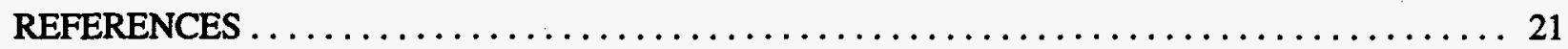




\section{LIST OF FIGURES}

Figure

Page

1. Location of chocks vs von Mises-Hencky stress for single cylinders $\ldots \ldots \ldots \ldots \ldots$

2. Von Mises-Hencky stresses vs stiffening ring centerline spacing for stacked cylinders . . . 14 


\section{LIST OF TABLES}

Table

Page

1. Location of chocks vs von Mises-Hencky stress for single tier cylinders $\ldots \ldots \ldots \ldots$

2. Stress values for cylinder stacking calculations $\ldots \ldots \ldots \ldots \ldots \ldots \ldots \ldots \ldots \ldots \ldots$

3. Summary of breached cylinder load cases and stresses $\ldots \ldots \ldots \ldots \ldots \ldots \ldots \ldots$

4. Summary of cylinder lift cases and stresses $\ldots \ldots \ldots \ldots \ldots \ldots \ldots \ldots \ldots \ldots$ 



\title{
METHODS AND RESULTS FOR STRESS ANALYSES ON 14-TON, THIN WALL DEPLETED UF ${ }_{6}$ CYLINDERS
}

\author{
MODIFICATIONS AND ADDITIONS
}

\section{EXECUTIVE SUMMARY}

Uranium enrichment operations at the three U. S. Gaseous diffusion plants produce depleted uranium hexafluoride $\left(\mathrm{DUF}_{6}\right)$ as a residual product. At the present time, the inventory of $\mathrm{DUF}_{6}$ in this country is more than half a million tons. Most of the inventory of $\mathrm{DUF}_{6}$ is contained in cylinders made of carbon steel that are stored in "yards" which are open to the weather. Thus, corrosion of the storage cylinders is a matter of concern. DOE is funding a long term project whose objective is to manage the DUF $_{6}$ storage cylinders in a way that should prevent an environmental hazard that would be caused by releasing their contents to the atmosphere and also in a way so that the $\mathrm{DUF}_{6}$ may eventually be converted to a less hazardous material for final disposition.

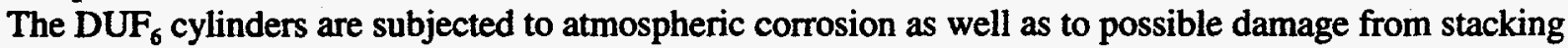
and other handling operations. An important task in the $\mathrm{DUF}_{6}$ cylinders management project is determining how much corrosion of the walls can be tolerated before the cylinders are in danger of being damaged during

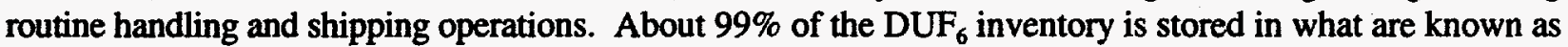
10-ton and 14-ton cylinders. There are about 50,000 of these cylinders in service at this moment. These cylinders have a nominal diameter of $48 \mathrm{in}$. About $92 \%$ of the DUF ${ }_{6}$ inventory is stored in models of the 14ton, thin-wall cylinders.

Because the 14-ton, thin wall cylinders contain the bulk of the DUF 6 inventory, most calculations of cylinder stresses due to handling have been done for that type of cylinder. The present report documents as many of the FESA cases done at Oak Ridge for 14-ton, thin-wall cylinders as possible, giving results and a description of the calculations in some detail. A set of calculations was done to determine what location of the chocks that support the bottom row of cylinders would give the lowest stress on the cylinders. The conclusion is that the chocks should be outside the stiffening rings, but as close as possible to them. Calculations were done of the stresses that come from having cylinders stacked in two-high tiers as is the usual practice in the cylinder storage yards. One conclusion of the study is that modeling the fillet weld between the stiffening ring and the shell has a large effect on the calculated stresses and on the conclusion of the study. For the best model, the conclusion is that the cylinders should be stacked so that the stiffening rings are as close to one another as is practicable. Calculations were done of the stresses that various lifting methods might impose on four cylinders that have been breached. The results indicate which lifting methods would keep the stresses low enough so that the breaches should not increase in size. Calculations were done to determine the stresses imposed on corroded, but not breached cylinders from lifting by the lugs and also on an almost uncorroded cylinder (shell thickness $1 / 4$ in., which is the minimum thickness allowable for inter-plant shipping according to the ANSI standard for shipping) from lifting by the Raygo-Wagner stacker. Results suggest that cylinders with a high level of corrosion on the bottom portion of the cylinder (shell thickness as small as 1/16 in.) can be safely lifted by the lugs. Stresses imposed on the cylinder with a 1/4-in. thick shell by the RaygoWagner stacker were lower than the yield so that a shell that thick should be in no danger of unacceptable deformation from lifting by the Raygo-Wagner stacker. 


\section{INTRODUCTION}

Uranium enrichment operations at the three U.S. gaseous diffusion plants produce depleted uranium hexafluoride $\left(\mathrm{DUF}_{6}\right.$ ) as a residual product. At the present time, the inventory of DUF $\mathrm{F}_{6}$ in this country is more than half a million tons. The inventory of DUF $_{6}$ is contained in metal storage cylinders, most of which are located at the gaseous diffusion plants.

Most of the 48-in. DUF 6 storage cylinders are made of carbon steel. Most of the cylinders are stored in "yards" that are open to the weather, thus corrosion of the storage cylinders is a matter of concern. DOE is funding a long term project to manage the $\mathrm{DUF}_{6}$ storage cylinders. The principal objective of the project is to ensure the integrity of the cylinders to prevent causing an environmental hazard by releasing the contents of the cylinders into the atmosphere. Another objective is to maintain the cylinders in such a manner that the DUF $_{6}$ may eventually be converted to a less hazardous material for final disposition.

About $92 \%$ of the DUF 6 inventory is stored in what are known as 14-ton thin-wall cylinders. There are nearly 50,000 of these cylinders in existence at present. These cylinders, which have a nominal diameter of $48 \mathrm{in}$. and nominally contain 14 tons of DUF ${ }_{6}$, were originally designed and fabricated for temporary storage of DUF ${ }_{6}$, although the rules for shipping of cylinders ${ }^{1}$ allow these to be shipped if they are in good enough condition. They were fabricated from pressure-vessel-grade steels according to the provisions of the ASME Boiler and Pressure Vessel Code. ${ }^{2}$ As built, the thin-wall cylinders have a 5/16-in. wall thickness.

In addition to the 14-ton thin-wall cylinders, there are also 14-ton thick-wall (5/8-in. wall thickness) cylinders and 10-ton cylinders with both thick and thin walls. The 10-ton cylinders have the same 48-in. diam as the 14-ton models but are shorter. Counting the many different models of thin- and thick-wall 10- and 14ton cylinders, about $99 \%$ of the total $\mathrm{DUF}_{6}$ inventory is contained in 48-in.-diam cylinders.

Most of the 48-in. DUF ${ }_{6}$ cylinders are stored outdoors in two-tier arrays, with the contacts between upperand lower-tier cylinders being shell-to-stiffener rings. The lower-tier cylinders are supported by chocks. The use of the word "chocks" comes from a time when it was common to let storage and shipping cylinders rest on the ground with wooden wedges ("chocks") on either side to keep them from rolling. At present, most cylinders rest on wooden or concrete saddles (which are still called chocks) rather than on the ground. Although it is common to speak of the cylinders or chocks resting on the "ground," there are few cylinders in storage yards that are surfaced with dirt. Instead, almost all cylinder storage places are paved with gravel, asphalt, or concrete. The cylinders are subjected to atmospheric corrosion as well as to possible damage from stacking and other handling operations. An important task in the DUF 6 cylinders management project is determining how much corrosion of the walls can be tolerated before the cylinders are in danger of being damaged during routine handling and shipping operations. Another task is determining how to handle cylinders that have already been damaged in a manner that will minimize the chance that a breach will occur or that the size of an existing breach will be significantly increased.

A number of finite element stress analysis (FESA) calculations have been done to analyze the stresses for three conditions: (1) while the cylinder is being lifted, (2) when a cylinder is resting on two cylinders under it in the customary two-tier stacking array, and (3) when a cylinder is resting on its chocks on the ground. Most of the FESA calculations at Oak Ridge have been done by Dr. C. K. Chung ${ }^{3,4,5,6,7}$ of the Technical Support Organization at K-25. Because the 14-ton thin-wall models represent the vast majority of the cylinders in the inventory, the FESA calculations have been done for that kind of cylinder. Various documents describe some of the results and discuss some of the methods whereby they have been obtained. The objective of the present report is to document as many of the FESA cases done at Oak Ridge for 14-ton thin-wall cylinders as possible, giving results and a description of the calculations in some detail. 


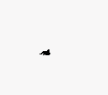




\section{ASSUMPTIONS}

The pressure vessel-grade steels used for construction of the cylinders are assumed to have nominal values of $30 \times 10^{6} \mathrm{lbs} / \mathrm{in} .^{2}$ for the modulus of elasticity and 0.3 for Poisson's ratio. 


\section{MODELING OF THE FINITE ELEMENT PROBLEMS}

The cylinder assemblies are fabricated of 5/16-in.-thick plates for the shell, three 2-1/2 $\times 1$-in.-thick stiffener rings (some rings are 7/8-in. wide, but the width in Dr. Chung's calculations is 1 in.), and two $2: 1$ ellipsoidal heads. (Some cylinders in the inventory have two stiffening rings. Many of the results from this work will not be applicable to those, although it should be possible to correct some of the results for the different number of rings.) The nominal outside diameter is $485 / 8$ in. Since the geometry and loadings are symmetrical with respect to a plane containing the centerline of the middle stiffener ring, half of the cylinder (in the axial direction) is modeled for the analysis. Although the as-built shell thickness is $5 / 16(0.3125)$ in., the objective of most of the FESA calculations is to examine the stresses in cylinders that have been corroded. Thus, there are very few calculations with the full as-built thickness. The standards for cylinder shipping and handling, ANSI N14.1 ${ }^{1}$ and ORO-651, ${ }^{8}$ both specify that a 14-ton thin-wall cylinder with a minimum wall thickness of $0.250 \mathrm{in}$. or greater can be shipped outside the gaseous diffusion plants. Therefore, many of the sets of FESA calculations do not use a shell thickness greater than 0.250 in. If a case is specified as having a uniform thickness, then both the shell and the head have that thickness. For cases where parts of the shell are thinner than others, the head elements have the same thickness as the adjacent shell elements. The cases were generated with the nominal (48 5/8-in.) outer diameter. Cases with a thickness less than 5/16 in. used this outer diameter and increased the inner diameter. Although actual cylinders corrode from the outside in, the difference between stresses calculated for constant inner diameter and constant outer diameter should be trivial.

The right-hand coordinate system of the computer model defines the direction of gravitational acceleration as negative in the $y$-axis, and the centerline of the cylinder axis is in the $x$-axis. The static analyses are performed with the consistent mass model by the Engineering Mechanics Research Corporation (EMRC) NISA II program. .,10 $^{2}$

The FESA model has three-dimensional solid, shell, and beam elements. The weight of the DUF 6 content is simulated by a line element located at the centerline of the cylinder and extending the axial length of the cylinder. Weightless line elements fan out from the central mass line element to selected nodal points on the shell providing links from the central mass line element to the shell nodes, thereby distributing the weight of the DUF $_{6}$ to the shell. Each of the axial nodes of the line element is connected to 13 nodes on the shell by the weightless line elements. The 13 shell nodes per axial node are separated from one another by an angle of $15^{\circ}$. The mass line element representing the DUF 6 was put on the centerline for computational convenience. It might be slightly more accurate to put the mass line element at the location of the top of the DUF $_{6}$, which is about 5 in. above the centerline. The combination of the mass line element and the set of weightless line elements going to the shell simulates the "hydrostatic" force from the weight of the DUF. Placing the line element on the centerline means that all of that force is transmitted to the bottom half of the shell rather than part of it appearing above the centerline. (The total force is the same in either case because the weight of the line element is adjusted to be equal that of the $\mathrm{DUF}_{6}$.) Having the hydrostatic force applied to the bottom half should tend to raise the calculated stresses on the shell slightly. Thus, having the mass line element at the centerline is a conservative approximation.

For calculations of the stresses resulting from shell to stiffener contact, there are separate portions of the computing model representing the two cylinders. Because ideally the contact between an upper row cylinder and the two lower row cylinders on which it rests is symmetric about the vertical plane through the centerline of the upper cylinder, it is only necessary to simulate contact of half of the upper cylinder with one adjacent lower cylinder. For each contact area it is necessary that nodes on the portion of the model representing the shell be connected to nodes on the portion representing the stiffening ring. The computing mesh has been constructed so that each contact area is represented by nine nodes on the stiffening ring opposite nine nodes of almost identical spacing on the corresponding portion of the shell. Each of these contact areas is 1 in. in the axial direction (i.e., the width of the stiffening ring) by $3 / 8$ in. on the circumference. Each of the stiffening 
ring nodes is connected to its corresponding shell node by a rigid link. These links transmit the forces from one cylinder to another.

In the previous paragraph, it was stated that the cylinder calculations use half the length of the cylinders because the cylinder geometries are symmetric about the centerline of the middle stiffening ring. For stacking calculations, that symmetry argument is not correct. This is true because the cylinders are offset from one another in the axial direction in order that the stiffening rings will not make contact. For the FESA calculations, Dr. Chung makes an approximation that a plane of symmetry exists at the centerline of the upper cylinder. The finite element meshes are constructed so that the upper cylinder overhangs the lower one by the distance the rings are offset (i.e., the half of the upper cylinder is that distance longer than the half of the lower cylinder). In effect, Dr. Chung is treating the lower cylinder as if it were twice the offset distance shorter than the upper. However, the length of the upper cylinder, and therefore its weight, is correct. For stacking calculations, the maximum stresses occur at the contact patches near the ends. These stresses are due to the weight of the upper cylinder. Therefore, the error that the shorter lower cylinder approximation introduces in the maximum stresses should be minor.

The lifting lugs are included in the finite element mesh. However, the hole in the lifting lug into which the lifting tackle fits is not simulated. Instead, a single finite element node at the location of the center of the hole has the lifting force applied to it. Although this approximation leads to a stress at the hole that is much higher than is physically justified, the stresses in the lifting lug are small enough that the overly large stress does not matter. In accordance with Saint Venant's principle, the stress field "far away" from the hole in the lug should be independent of the details of the application of the lifting force provided that the magnitude and direction of the force are correct, as they are for Dr. Chung's FESA calculations.

For calculations of stresses from having the cylinders rest on chocks or be lifted by straps or the Raygo-Wagner lifter, the weight is transmitted from the cylinder to the support by restraints from the bearing surface to the shell nodes that are in contact with the bearing surface. Depending on the kind of bearing surface, the restraints can be rigid (thereby simulating a rigid bearing surface) or may be flexible (thereby simulating a more compliant bearing surface). The degree of flexibility is expressed as a spring rate for the flexible link. All other things being equal, one would expect that the stresses at the edges of the area connected to the bearing surface would be greater for rigid restraints than for flexible ones. Therefore, simulating contact with a bearing surface by rigid restraints should be conservative. The flexible supports should simulate the wooden chocks, whereas the rigid supports should better model the concrete chocks.

The method of calculation of the density for the content, $d_{\text {bar }}$ and for the shell, $d_{\text {shell }}$ follows. Maximum volume of the contents, $V$, for the type $48-\mathrm{G}$ or $48-\mathrm{OM}$ cylinder is $139.72 \mathrm{ft}^{3}$. The equivalent length, $L_{e}$, is defined as the length of a right circular cylinder of inside diameter 48 in. whose volume is $V$. It is found from the following volume calculation:

$$
V=139.72 \times 1728 \text { in. }^{3}=241,436.16 \text { in. }^{3}=\pi \times\left(r_{i}\right)^{2} \times L_{e} .
$$

Therefore,

$$
\begin{aligned}
L_{e} & =241,436.16 /\left(3.14159 \times 24^{2}\right) \\
& =133.52288 \mathrm{in} ., \text { and } \\
d_{\text {shell }} & =490 /(1728 \times 32.174 \times 12) \\
& =7.34456 \times 10^{-4} \mathrm{lb}_{\mathrm{f}}-\mathrm{s}^{2} / \mathrm{in}^{4}
\end{aligned}
$$


The models have bar elements with cross-sectional areas of 1.000 in. $^{2}$ to represent the $\mathrm{UF}_{6}$ content weight.

$$
\begin{aligned}
d_{\text {bar }} & =28,000 \mathrm{lb}_{\mathrm{f}} /\left(\text { cross-sectional area } \times L_{e}\right) \\
& =28,000 /(1.000 \times 133.42288) \\
& =0.54355 \mathrm{lb}_{\mathrm{f}}-\mathrm{s}^{2} / \mathrm{in}^{4} .
\end{aligned}
$$





\section{RESULTS FROM STRESS ANALYSES}

\subsection{LOCATION OF THE WOODEN SUPPORT CHOCKS VS MAXIMUM STRESS FOR SINGLE TIER STORAGE CYLINDERS}

A set of calculations of stresses for a cylinder resting on its chocks was done. The objective of the calculations was to determine the effect of moving the location of the chocks, and in particular, to see if there is an optimum location for the chocks that would minimize the stresses. It is tacitly assumed that the distribution of the stresses should be more or less independent of the wall thickness. Therefore, all the cases were done for a uniform shell thickness of 0.250 in. with the chocks set at different support locations. A secondary objective was to see how the stresses responded to some modeling details-specifically, whether the chock was modeled as a rigid or flexible support, and whether the intersection between the shell and the stiffening ring was modeled as a sharp corner or with a rounded fillet weld. No attempt was made to determine whether these two modeling details would change the chock location that led to minimizing the stresses. The calculation with flexible restraints used a spring rate of $1.0 \times 10^{6} \mathrm{lb} /$ in. Although the nominal width of the chocks is 7 in., the simulation assumed a 5-in. bearing surface which is a conservative approximation allowing for deterioration of the surface of the wooden chocks with time. The summary of computations with the maximum von Mises-Hencky (M-H) stress (the maximum M-H stress is very close to the maximum shear stress) vs the location of the chock is provided on Table 1 and is plotted on Fig. 1. It can be concluded that the best location of the chock (in terms of minimizing stress) is outside the stiffening ring but as close to the ring as feasible.

The first three entries in Table 1 show the sensitivity of the maximum stress values to whether the chock model is rigid or flexible and whether the intersection of the stiffening ring and the shell is modeled as a fillet weld of finite radius ( 0.250 in.) or as a sharp corner. The approximately $15 \%$ loss in maximum stress going from the flexible chock model of case FWS250 to the rigid model of case FWR250 is counter to intuition. The reason for the lowered stress in the rigid model is that the unsupported force in the azimuthal region beyond the bearing surface applies a torque about the line dividing the supported shell from the unsupported shell. This torque means that the forces on the links in the supported region are less than those given by the "hydrostatic" force from-the weight of the cylinder and the DUF. This tends to try to lift the nodes in the supported region off the bearing surface. However, the rigid links do not allow the shell nodes to lift away from the bearing surface; therefore, the shape of the shell in the axial plane of the chock is a perfect circle until the "knife edge" representing the edge of the chock. Therefore, there is no bending moment until the "knife edge" is reached. By contrast, the springs in the flexible model allow a flexing of the shell and a consequent buildup of bending moment, thus allowing a larger bending stress at the line where the shell becomes unsupported. Thus, the low stress in the rigid support case is an artifact of the rigid link. Although such a model may not be possible with the NISA code as currently written, it would seem that a more reasonable model for a rigid support would allow the links to support force in compression, but no force in tension. The comparison between these first three cases is not intended to give a "best" answer, but rather, to indicate the uncertainty in calculated stresses that comes about from details of the modeling process.

All but the first two and last entries in Table 1 represent a study of the maximum stresses vs chock location for a single cylinder resting on a pair of chocks. The objective is to determine where to place the chocks for the least stress on the cylinder and also to determine whether there are chock locations that cause high enough stresses that they should be avoided. None of the calculated stresses for a 0.250 -in.-thick shell are anywhere close to yield values. Even with the load on the chock doubled to allow for stacking the cylinders in two rows (doubling the stress is a very conservative approximation for the maximum stress on a cylinder with another stacked on top of it), the stresses do not approach yield. Thus, for cylinders with a thickness of at least $\mathbf{0 . 2 5 0} \mathrm{in}$, it does not matter very much where the chocks are placed. However, for badly corroded cylinders the stress will increase as the thickness decreases. According to the results of this study, badly 
corroded cylinders should be placed on chocks that are spaced in such a way that the chocks are outside the stiffening rings but as close to the rings as possible.

Table 1. Location of chocks vs von Mises-Hencky stress for single tier cylinders

\begin{tabular}{|c|c|c|c|c|}
\hline File name & $\begin{array}{l}\text { Distance between } \\
\text { centerlines of ring } \\
\text { and chock } \\
\text { (in.) }\end{array}$ & $\begin{array}{l}\text { Wooden chock } \\
\text { model }(\mathrm{R}=\text { rigid } \\
\text { support, } \mathrm{F}= \\
\text { flexible support) }\end{array}$ & $\begin{array}{c}\text { Fillet weld } \\
\text { modeled at } \\
\text { plate and ring } \\
\text { contact }\end{array}$ & $\begin{array}{c}\text { Maximum } \\
\text { von } \\
\text { Mises-Hencky } \\
\text { Stress } \\
\text { (ksi) }\end{array}$ \\
\hline FS250H & -4.5 & $\mathbf{F}$ & No & 6.36 \\
\hline FWS250 & -4.5 & $\mathbf{F}$ & Yes & 6.72 \\
\hline FWR250 & -4.5 & $\mathbf{R}$ & Yes & 5.71 \\
\hline FWR25a & -5.5 & $\mathbf{R}$ & Yes & 6.40 \\
\hline FWR25b & -6.5 & $\mathbf{R}$ & Yes & 6.68 \\
\hline FWR25d & -8.5 & $\mathbf{R}$ & Yes & 7.25 \\
\hline FWR25g & -11.5 & $\mathbf{R}$ & Yes & 8.96 \\
\hline FWR-S0 & 4.5 & $\mathbf{R}$ & Yes & 9.49 \\
\hline FWR-Sa & 5.5 & $\mathbf{R}$ & Yes & 11.99 \\
\hline FWR-Sb & 6.5 & $\mathbf{R}$ & Yes & 11.66 \\
\hline FWR-Sc & 7.5 & $\mathbf{R}$ & Yes & 10.65 \\
\hline FWR-Sd & 8.5 & $\mathbf{R}$ & Yes & 9.70 \\
\hline $\mathrm{FS} 250 \mathrm{q}$ & -4.5 & $F$ & Yes & 11.28 \\
\hline
\end{tabular}

a The cylinder is supported by wooden chocks 7 in. wide $\times 8.5$ in. high. The stiffening ring is 1 in. wide, therefore, a centerline spacing of 4 in. represents contact between the vertical faces of the ring and the chock. Negative values denote chock locations outside the ring; positive values indicate distances inside the ring (toward the center of the cylinder). The actual bearing surface in the FESA calculations is 5 in. in width with an angle in the azimuthal direction of $60^{\circ}$ (which corresponds to a total distance in the azimuthal direction of 50.59 in. for a complete cylinder and half that amount for a cylinder split in half on a vertical plane parallel to the axis). 


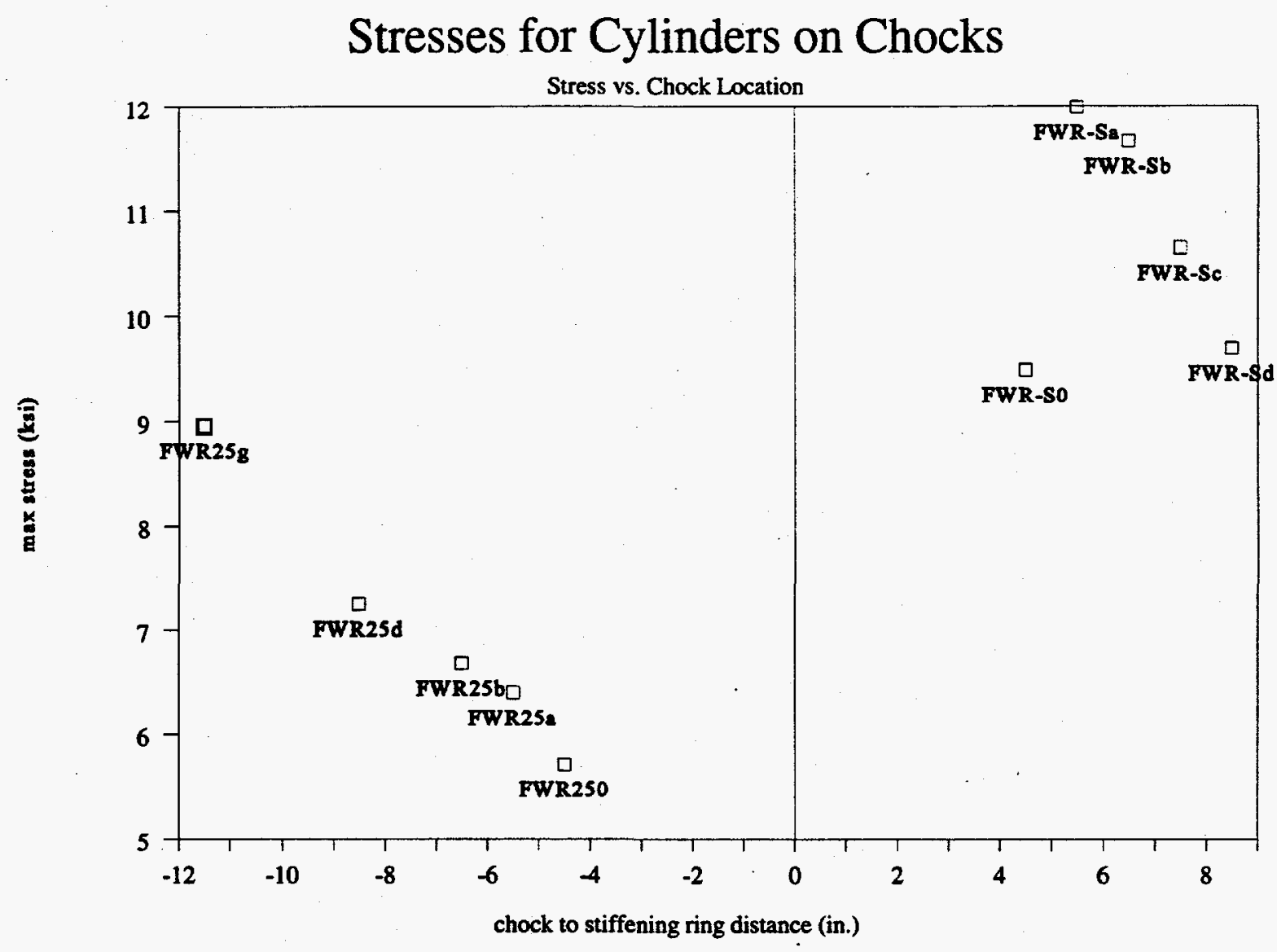

Fig. 1. Location of chocks vs von Mises-Hencky stress for single cylinders. Distances measured from centerline of 1 -in.-wide stiffening ring to centerline of 7-in.-wide chock. Values of chock location less than 0 imply chocks located outside the stiffening ring. 
The shape of the curve of stress vs distance from the stiffening ring is hard to explain. Although the authors do not have good reason to believe that the FESA results are in error, they cannot explain the sharp rise in stress going from outside the ring to just inside the ring. However, some results from the classic paper by Zick ${ }^{11}$ may help provide a partial explanation. Zick's paper includes results for stress vs chock location for cylinders with no stiffening rings. It also shows results for geometries where the rings and chocks are coincident. It does not show any results for cylinders with rings that are not coincident with the chocks. Therefore, one must be a bit careful using Zick's results in a discussion of results from the present study. However, one may draw two conclusions from Zick's discussion of the effect of stiffening rings. First, if the chocks are far enough away from the rings, the stresses with and without rings should not be very different. Second, because stiffening rings allow a transfer of force from the bottom of the cylinder to the top, the presence of rings should lower the maximum stresses. In a cylinder with no stiffening rings, a plot of longitudinal bending moment vs distance of the chocks from the ends (Zick, Fig. 5) shows falling stress until a certain chock spacing is reached and then shows a rise. As has already been stated, the maximum stresses for chocks near the rings are smaller than for a cylinder with no rings. The chock spacing that corresponds to a stress minimum for a cylinder with chocks placed at the stiffening rings is quite a bit smaller than the spacing that achieves a minimum for an unstiffened cylinder. The stiffened cylinder minimum occurs at just about the location of the stiffening rings for a 48-in., 14-ton DUF 6 cylinder. No doubt the people who designed the cylinders were familiar with Zick's work (which, according to the Pressure Vessel Handbook has been adopted by ASME as recommended design practice) and placed the rings at the "optimum" location. It would be fair to say that the cylinders are designed to have the chocks as close to the rings as possible. The shape of the curve of stress vs chock location for chocks outside the ring confirms this. The sharp rise in stress for chocks located just inside the ring remains unexplained.

\subsection{MAXIMUM STRESS VS LOCATION OF THE STACKED CYLINDER}

The 48-in. cylinders are customarily stacked in two tiers, one upon the other, so that the stiffening rings bear on the shells. The centerlines of an upper-row cylinder and the two lower-row cylinders on which it rests make an isosceles triangle with two nominally $52.5^{\circ}$ angles. Sets of FESA calculations were done to determine the maximum stresses that occur from having the cylinders stacked in this manner. Table 2 shows results from the FESA calculations of this configuration.

The most important independent variables are the separation between the stiffening rings and the thickness of the cylinders. In Table 2 cases with file names ending with " $F W$ " denote models with a fillet weld of 0.250 in. on both sides of the stiffener. The file names with "S6L" and "S25L" represent stiffener spacings of 6.000 and $1.250 \mathrm{in}$., respectively, between the centerlines of the bottom ring and the top ring. The ring centerline spacing of $1.250 \mathrm{in}$. for cases whose names begin with "S25L" represents a spacing of $0.250 \mathrm{in}$. between the faces of the stiffening rings. Because the fillet welds have a 0.250 -in. radius, this spacing represents the closest the rings can approach one another without having a ring rest on part of the fillet weld.

The maximum stress occurs where the stiffening rings of the upper cylinder bear on the shells of the lower cylinders (because the geometry is nominally symmetric about the center plane of the upper cylinder, there are identical contact areas on each of the two lower cylinders). Comparison of cases S6L250FW, S6La25FW, and S6Lb25FW indicates that the location of the chocks has very little effect on the maximum stresses. The first three cases shown in Table 2 (S6L188FW, S6L250FW, and S6L312FW) examine the effect of shell thickness on the calculated stress for a stiffening ring separation of 6 in. and a fillet weld. It can be demonstrated that, within a few percentage points, the maximum stresses from these three cases are proportional to the reciprocal of shell thickness. The results from cases S6L250 and S6L188 indicate that stress is inversely proportional to wall thickness for calculations with a 6-in. stiffening ring separation but without a fillet weld. Cases S25L25, S25L20, and S25L17 examine the effect of shell thickness on the calculated stress for a stiffening ring separation of $1.25 \mathrm{in}$. with no fillet weld. For these cases, the maximum 
stresses are proportional to the reciprocal of shell thickness raised to about the power of 1.34 . The reader may note that the calculated M-H stresses for the last three cases are much higher than the 24 ksi yield for A-285 grade C steel. However, omitting the fillet weld for cases with the rings this close together represents a poor model so that those calculations and the resultant high calculated stresses are not relevant.

Table 2. Stress values for cylinder stacking calculations

\begin{tabular}{|c|c|c|c|c|}
\hline File name $^{a}$ & $\begin{array}{c}\text { Offset distance } \\
\text { between two } \\
\text { cylinders }^{b}(R+R) \\
\text { (in.) }\end{array}$ & $\begin{array}{l}\text { Location of } \\
\text { wooden chock } \\
\text { (in.) }\end{array}$ & $\begin{array}{c}\text { Fillet weld } \\
\text { modeled at } \\
\text { plate and ring } \\
\text { contact } \\
\end{array}$ & $\begin{array}{c}\text { Maximum von } \\
\text { Mises-Hencky } \\
\text { stress } \\
\text { (ksi) }\end{array}$ \\
\hline $\begin{array}{l}\text { S6L188FW } \\
\text { (0.188 in.) }\end{array}$ & -6 & -4 & Yes & 28.74 \\
\hline S6L250FW & -6 & -4 & Yes & 21.31 \\
\hline $\begin{array}{l}\text { S6L312FW } \\
\text { (0.312 in.) }\end{array}$ & -6 & -4 & Yes & 16.46 \\
\hline S6La25FW & -6 & 4 & Yes & 21.8 \\
\hline S6Lb25FW & -6 & 7.5 & Yes & 22 \\
\hline $\mathrm{S} 6 \mathrm{~L} 250^{d}$ & -6 & -4 & No & 23.21 \\
\hline $\begin{array}{l}\text { S6L188 } \\
\text { (0.188 in.) }\end{array}$ & -6 & -4 & No & 30.2 \\
\hline S4L250FW' & -4 & -4 & Yes & 20.41 \\
\hline $\mathrm{S} 2 \mathrm{~L} 250 \mathrm{FW}^{d}$ & -2 & -4 & Yes & 17.53 \\
\hline S25L25FW' & -1.25 & -4 & Yes & 16.03 \\
\hline $\mathrm{S} 25 \mathrm{~K} 25^{d}$ & -1.25 & -4 & No & 43.05 \\
\hline $\begin{array}{l}\text { S25L20 } \\
(0.200 \text { in. })\end{array}$ & -1.25 & -4 & No & 69.80 \\
\hline $\begin{array}{l}\text { S25L17 } \\
\text { (0.175 in.) }\end{array}$ & -1.25 & -4 & No & 83.79 \\
\hline
\end{tabular}

${ }^{a}$ Numbers in parentheses are (uniform) shell thicknesses. All other cases have 0.250 -in.- (uniform) thick shells.

${ }^{b}$ The horizontal offset distance between stiffening rings of the bottom cylinder and the top cylinder. The negative values denote that the top cylinder is in the negative $x$-direction from the bottom cylinder.

${ }^{c}$ The bottom cylinder is supported by the wooden chocks (7-in. width $\times 8.5$-in. height). It is assumed that the supporting region of the chock is a 5.0-in- wide saddle symmetrical with respect to the centerline of the width. Negative values indicate that the centerline of the chock is outside (cylinder-head side) of the centerline of the ring; and positive values indicate that the chock is toward the center of the cylinder.

- $\quad$ Points used for Fig. 2. 
The models with the fillet weld yield relatively lower contact stresses than models without the weld. At the 6-in. ring spacing, the difference is small (compare cases S6L250FW and S6L250). However, for the 1.25in. spacing, the stress for the fillet weld case is less than half that for the case without the fillet weld (compare cases S25L25FW and S25L25). The maximum stresses fall as the rings are moved closer together for cases with the fillet weld (compare cases S6L250FW, S4L250FW, S2L250FW, and S25L25FW). However, for cases without the weld, the maximum stress rises rapidly as the rings are moved closer together (compare cases S6L250 and S25L25). Figure 2 shows plots of the maximum stress as a function of stiffening ring separation. Clearly, at small ring separations, the details of the configuration at the junction of the ring and the shell are important.

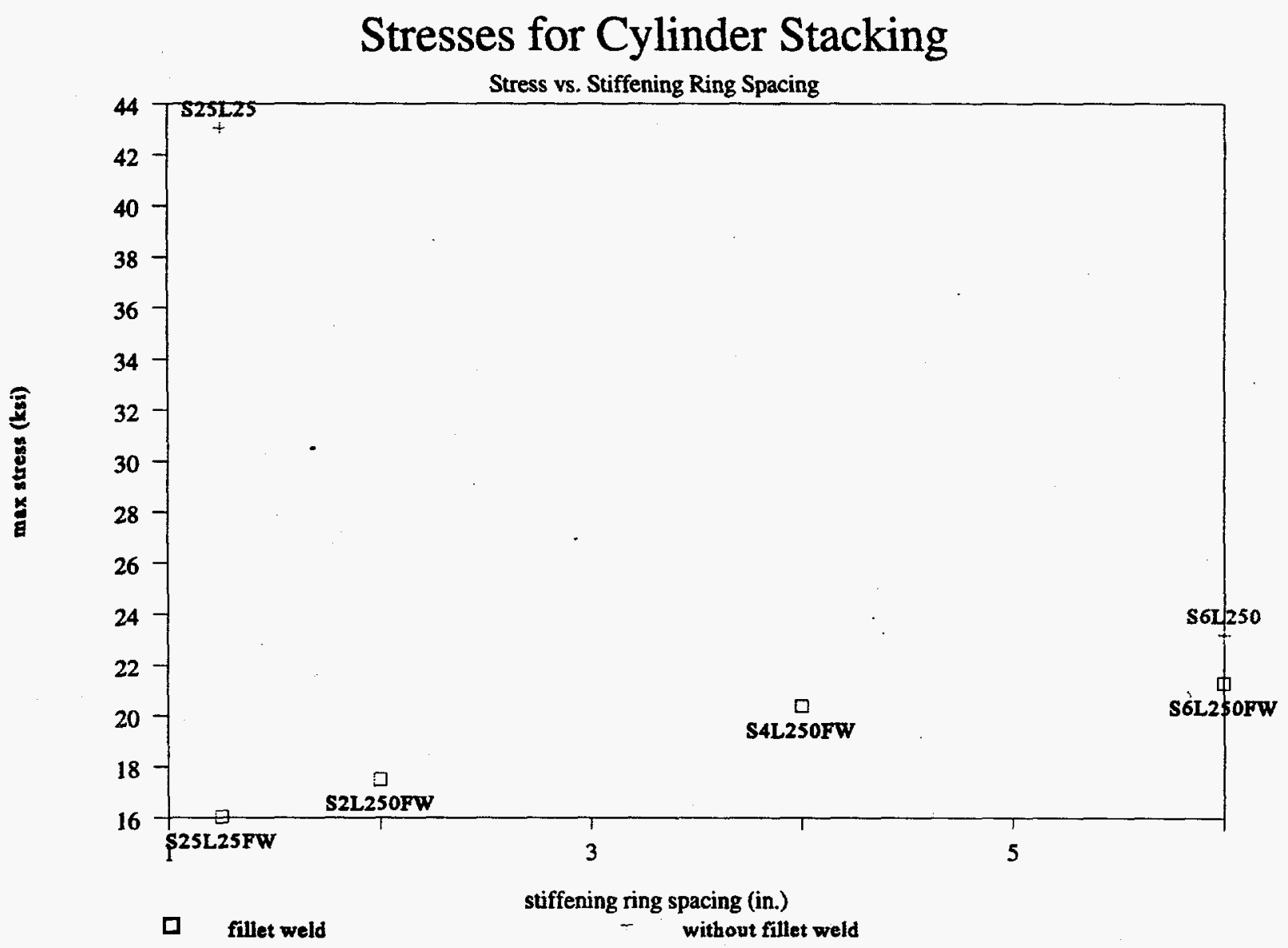

Fig. 2. Von Mises-Hencky stresses vs stiffening ring centerline spacing for stacked cylinders. 


\subsection{LIFTING OF BREACHED CYLINDERS}

Stresses have been analyzed for the lifting of four breached $\mathrm{UF}_{6}$ cylinders. Lifts have been analyzed using lifting lugs, a crane with straps, and the Raygo-Wagner and Allied Wagner cylinder carriers. The summary of load cases and stresses are provided in Table 3.

Cylinder stresses were computed by FESA. A uniform shell thickness of 0.250 in. was used for the calculations except for the thinned regions adjacent to the breached areas of the cylinders. The thinned region was modeled as a border around the breach having a thickness of the thinnest measurement reported as shown by mininum shell thickness measured in Table 3 . The maximum calculated stresses occur in the cylinder shell adjacent to the breached areas and are presented in Table 3 . The load cases and computed stresses in Table 3 provide either a "recommended" or "not recommended" opinion for a particular cylinder and lift condition. The maximum acceptable stress for a recommended lift condition is below material yield strength (30 ksi for A-285 C steel). The dimensions of the bearing surface of the Raygo-Wagner stacker have already been described. The straps were nominally 6 in. in width. Because the finite element mesh was not adjusted with changes in strap location, the actual bearing surface was usually somewhat narrower. The azimuthal extent of the straps was a full $180^{\circ}$. The straps were simulated with flexible links.

\subsection{LIFTING OF CYLINDERS WTTH SHELLS INTACT}

Some calculations were done to obtain stresses for lifting of intact (i.e., not breached) cylinders. Most of the cases were done to see what the effect would be of lifting cylinders that had been badly corroded by their lugs. In addition, a case simulating lift by the Raygo-Wagner stacker was done to compare the stresses imposed by that form of lift. The cases and their results are summarized in Table 4. The nominal bearing surface for the Raygo-Wagner stacker in the model is 4 in. (axial direction) by 14 in. (azimuthal direction). The edge of the bearing surface nearest the outer stiffening ring was 8 in. from the centerline of the ring. The edge of the bearing surface nearest the bottom of the cylinder (in the vertical direction) was at $41.25^{\circ}$ from the bottom. The surface covered an angle of $33.75^{\circ}$. The links providing the lifting force were those whose position on the surface of the cylinder was within the bounds of the nominal bearing surface. However, the nodes under the bearing surface were not moved to match the bounds of the bearing surface.

The actual magnitude of the area of the bearing surface was not the same as the nominal. There are nominally four bearing surfaces per cylinder. However, for computational convenience, it was assumed that the stress field was symmetric in the axial direction about the plane of the middle stiffening ring and also in the azimuthal direction about a vertical plane through the axis of the cylinder. The assumption of symmetry about the vertical plane is not correct because the tines of the Raygo-Wagner stacker are slightly offset in the axial direction. Dr. Chung's belief is that this is a minor error. The maximum stresses occur under the bearing surface of the tines, which is more than $40^{\circ}$ in the azimuthal direction from the central plane. The stresses at the plane of symmetry are much lower, which supports the belief that the error from the symmetry assumption is not significant. The Raygo-Wagner lift was simulated with flexible links of high spring constant.

The stress values shown in Table 4 are less than the ASME code allows for A-285 grade C or A-516 grade 55 (for both materials, the allowable is $13.8 \mathrm{ksi}$ ). The four cases with lifting lugs indicate that, even for severely corroded cylinders, the stresses from lifting by lugs are far less than the allowable. The highest stress comes from case RWA25h, which simulates lifting a cylinder of shell thickness 0.125 in. with the RaygoWagner stacker. The magnitude of that stress suggests that lifting severely corroded cylinders with the RaygoWagner carrier might exceed the allowable stress. However, as was described in Kirkpatrick's review, ${ }^{12}$ the allowable stresses for lifting operations for vessels that are not under internal pressure are about 4.5 times the stresses that ASME allows for vessels under pressure. The origin of this value is explained in the report written by Wilkowski, et al. ${ }^{13}$ at Battelle in October, 1992. If one accepts the multiplier of 4.5 for allowables for nonpressurized lifting, then it should be safe to lift severely corroded cylinders with the Raygo-Wagner 
stacker. The reader may note that the allowable stresses for cylinders not under pressure proposed by Wilkowski, et al., are higher than the yield stress. The tacit assumption is that local yielding of a cylinder not under pressure is acceptable. 
Table 3. Summary of breached cylinder load cases and stresses

\begin{tabular}{|c|c|c|c|c|c|c|}
\hline $\begin{array}{l}\text { Cylinder ID } \\
\text { (type) }\end{array}$ & File name & Lifitng device & $\begin{array}{c}\text { Minimum shell } \\
\text { thickness } \\
\text { measured" } \\
\text { (in.) }\end{array}$ & $\underset{(p s i)}{\text { Maximum stress }}$ & $\begin{array}{l}\text { Position of the lifting } \\
\text { devices on the cylinder }\end{array}$ & $\begin{array}{l}\text { Recommendation on using lifting } \\
\text { device }\end{array}$ \\
\hline \multirow{4}{*}{$\begin{array}{c}114951 \\
(48-\mathrm{OM})\end{array}$} & R14951 & Lugs & 0.120 & 25,398 & Lugs" & Not recommended \\
\hline & A14951 & Straps & 0.120 & 6,752 & $x \mathrm{xl}=(-) 9.0^{\prime \prime}$ to $(-) 11^{\prime \prime}$ & $\begin{array}{l}\text { Recommended } \\
\text { use } 6^{\prime \prime} \times 30^{\prime} \text { straps }\left(3.4^{\circ}\right) \text {, } \\
\text { (See note } c \text { ) }\end{array}$ \\
\hline & $\$ 14951$ & Straps & 0.120 & 6,717 & $\begin{array}{l}x 1=17.0^{\prime \prime}, \text { and } \\
\times 2=82.0^{\prime \prime} \text { to } 88.0^{\prime \prime}\end{array}$ & $\begin{array}{l}\text { Recommended (use the same straps } \\
\text { as above) }\end{array}$ \\
\hline & B14951 & Raygo-Wagner & 0.120 & 6,314 & $\cdot$ & $\begin{array}{l}\text { Not recommended } \\
\text { (See note } i \text { ) }\end{array}$ \\
\hline \multirow{3}{*}{$\begin{array}{l}101244 \\
(48-O M)\end{array}$} & 101244 & Straps" & 0.050 & 22,960 & $\mathrm{xl}=7.50^{\prime \prime}$ & $\begin{array}{l}\text { Recommended; } \\
\text { use } 6^{\prime \prime} \times 10^{\prime \prime} \text { straps }\left(2.7^{\circ}\right) \text { or } \\
6^{\prime \prime} \times 15^{\prime \prime} \text { straps }\left(1.8^{\circ}\right)\end{array}$ \\
\hline & 1R1244 & Raygo-Wagner & 0.050 & 22,960 & $\begin{array}{l}\text { Set the Raygo- Wagner centered } \\
\text { on the cylinder }\end{array}$ & Recommended \\
\hline & IL1244 & Lugs & 0.050 & 22,820 & Lugs & Recommended \\
\hline \multirow{3}{*}{$\begin{array}{l}7953 \\
(48-T)\end{array}$} & $7953 A$ & Lugs & 0.109 & 33,530 & Lugs & Not recommended \\
\hline & $7953 \mathrm{~S}$ & Straps ${ }^{*}$ & 0.109 & 23,460 & $x 1=1.0^{\prime \prime}$ & $\begin{array}{l}\text { Recommended; } \\
\text { use } 6^{\prime \prime} \times 15^{\prime \prime} \text { straps }\left(3.3^{\circ}\right)\end{array}$ \\
\hline & 7953RW & Raygo-Wagner & 0.109 & 23,490 & $\begin{array}{l}\text { Set the Raygo- Wagner centered } \\
\text { on the cylinder }\end{array}$ & Recommended \\
\hline $\begin{array}{l}116797 \\
(48-O M)\end{array}$ & None & Lugs, or Straps ${ }^{*}$ & 0.112 & $\begin{array}{l}\text { Stresses are lower than those } \\
\text { of cylinder 114951" }\end{array}$ & $x 1=83^{\prime \prime}$ to $89^{\prime \prime}$ for straps & $\begin{array}{l}\text { Recommend for straps and lugs; } \\
\text { use } 6^{\prime \prime} \times 10^{\prime \prime} \text { straps }\left(2.7^{\circ}\right)\end{array}$ \\
\hline
\end{tabular}

- Measurements were obtained from the $\mathrm{UF}_{6}$-cylinder wall thickness report.

A calculated equivalent uniaxial tensile stress adjacent to the breached area - von Mises-Hencky stress.

- Dimension $x_{1}$ or $x_{2}$ is measured from the plane of the stiffening ring nearest the plug to the close edge of the strap. If no value of $x_{2}$ is given, then second strap location should be determined in the field and should achieve a

kevel lift. If more than one value is given, the stresses represent those for the highest stress case. The other limit represents a location that is achievable with the straps given the position of the rings and breach.

- This lift is not recommended on the basis that the breach runs under the stiffening ring, which is not allowed. The recommendation is not based on calculated stress.

- Straps are placed symmetrically with respect to center of gravity except where $x_{2}$ is specified.

$f$ Estimated angle between the vertical axis and the strap/chain in the plane of the cylinder axis and vertical axis.

- For the alternate straps, if needed, 4 -in. wide or $2-f t$ long straps can be used.

This condition is to lift the plug end only to relocate the chock. It is to be used, if necessary, to achieve a vertical lift for the case 114951.

Recommends Raygo-Wagner for rotating, if necessary but not for carrying the cylinder. Recommendation for not carrying based on fact that Raygo-Wagner tines would bear on a wlded patch on the cylinder.

i Recommendations for cylinder 116797 are based on calculations of cylinder 114951 whose breach is the larger of the two, which implies that its stresses should also be larger. 
Table 4. Summary of cylinder lift cases and stresses

\begin{tabular}{|c|c|c|c|}
\hline File name & Lifting device & $\begin{array}{c}\text { Minimum shell } \\
\text { thickness } \\
\text { measured } \\
\text { (in.) }\end{array}$ & $\begin{array}{c}\text { Maximum stress } \\
\text { (ksi) }\end{array}$ \\
\hline H444LF & Lugs & 0.250 & 3.6 \\
\hline H441LF & Lugs & $\begin{array}{l}\text { Upper 1/3: } 0.250 \\
\text { Middle } 1 / 3: 0.250 \\
\text { Lower } 1 / 3: 0.0625\end{array}$ & 4.4 \\
\hline H432LF & Lugs & $\begin{array}{ll}\text { Upper 1/3: } & 0.250 \\
\text { Middle 1/3: } & 0.1875 \\
\text { Lower 1/3: } & 0.125\end{array}$ & 4.6 \\
\hline H321LF & Lugs & $\begin{array}{l}\text { Upper 1/3: } 0.1875 \\
\text { Middle 1/3: } 0.125 \\
\text { Lower 1/3: } 0.0625\end{array}$ & 6.3 \\
\hline RWA5h & Raygo-Wagner & 0.250 & 9.9 \\
\hline
\end{tabular}




\section{CONCLUSIONS}

A substantial number of FESA calculations have been performed for the 14-ton, thin-wall cylinders. A set of calculations was done to determine what location of the chocks that support the bottom row of cylinders would give the lowest stress on the cylinder. The conclusion is that the chocks should be outside the stiffening rings, but as close as possible to them. Calculations were done of the stresses that come from having cylinders stacked in two-high tiers, as is the usual practice in the cylinder storage yards. One conclusion of that study is that modeling the fillet weld between the stiffening ring and the shell has a large effect on the calculated stresses and on the conclusion of the study. For the best model, the conclusion is that the cylinders should be stacked so that the stiffening rings are as close to one another as is practicable. Calculations were done of the stresses that various lifting methods might impose on four cylinders that have been breached. The results indicate which lifting methods would keep the stresses low enough so that the breaches should not increase in size. Calculations were done to determine the stresses imposed on corroded, but not breached cylinders from lifting by the lugs and also on an almost uncorroded cylinder (shell thickness $1 / 4$ in., which is the minimum thickness allowable for inter-plant shipping according to the ANSI standard for shipping) from lifting by the Raygo-Wagner stacker. Results suggest that cylinders with a high level of corrosion on the bottom portion of the cylinder (shell thickness as small as 1/16 in.) can be safely lifted by the lugs. Stresses imposed on the cylinder with a 1/4-in. thick shell by the Raygo-Wagner stacker were lower than the yield so that a shell that thick should be in no danger of unacceptable deformation from being lifted by the RaygoWagner stacker. 


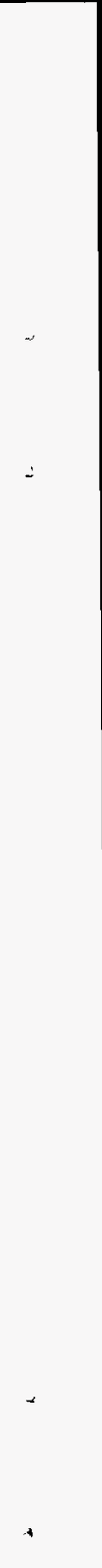




\section{REFERENCES}

1. American National Standards Institute, Uranium Hexafluoride-Packaging for Transport, N14.1-1990, ANSI, New York, 1990.

2. American Society of Mechanical Engineers, Boiler and Pressure Vessel Code, Sect. VIII, Div. I, and Sect. XI, ASME, New York, 1992.

3. C. K. Chung, J. L. Frazier, and D. K. Kelley, "Static Stress Analysis on the Large Capacity Thin Wall $\mathrm{UF}_{6}$ Cylinder," in Proceedings of the Third International Uranium Hexafluoride Conference: Processing, Handling, Packaging, and Transporting, Paducah, Kentucky, November 28-December 1, 1995.

4. J. L. Frazier, "UF 6 Cylinder Finite Element Analysis - DNFSB," letter to V. S. Newman, Lockheed Martin Energy Systems, Inc., Oak Ridge, TN, March 1, 1995.

5. J. L. Frazier, "UF 6 Handling by the Raygo-Wagner Stacker," letter to V. S. Newman, Lockheed Martin Energy Systems, Inc., Oak Ridge, TN, May 5, 1995.

6. J. L. Frazier, "UF 6 Handling by the Raygo-Wagner Stacker, Additional Analysis," letter to V. S. Newman, Lockheed Martin Energy Systems, Inc., Oak Ridge, TN, May 8, 1995.

7. J. L. Frazier, "Lifting of Breached Cylinders, Identification Number 114951, 101244, 7953, and 116797," letter to B. H. Howard, Lockheed Martin Energy Systems, Inc., Oak Ridge, TN, July. 13, 1996.

8. U.S. Department of Energy, Uranium Hexafluoride: A Manual of Good Handling Practices, ORO-651, Rev. 6, DE91015811, DOE Field Office, Oak Ridge, Tenn., 1991.

9. Engineering Mechanics Research Corp., NISA II, Ver. 91.0, Troy, Mich., 1994.

10. Engineering Mechanics Research Corp., Display II, Ver. II, Troy, Mich., 1994.

11. L. P. Zick, "Stresses in Large Horizontal Cylindrical Pressure Vessels on Two Saddle Supports," Welding Journal Research Supplement, 556-566, (1951).

12. J. R. Kirkpatrick, "Independent Review of Depleted $\mathrm{UF}_{6}$ Cylinder Storage Criteria," letter to V. S. Newman, Lockheed Martin Energy Systems, Inc., Oak Ridge, TN, December 12, 1995.

13. G. M. Wilkowski, N. D. Ghadiali, R. Mohan, and C. R. Miele, "Final Report on Structural Integrity Analysis of $\mathrm{UF}_{6}$ Storage Cylinder to Department of Energy Oak Ridge Field Office," Battelle, Columbus, OH, October 16, 1992. 


\section{INTERNAL DISTRIBUTION}

1. A. K. Balding

2. S. C. Blue

3. K. W. Childs

4-8. C. K. Chung

9. R. E. Dorning, II

10-14. J. L. Frazier

15. D. M. Hetrick

16. J. A. Horak

17. S. K. Iskander

18-19. M. L. Lykins

20-24. D. K. Kelley
25-29.J. R. Kirkpatrick

30. M. A. Kuliasha

31. D. L. Mason

32. S. J. Pawel

33. H. E. Philpott

34. R. I. Reynolds

35. M. S. Taylor

36. Central Research Library

37. Laboratory Records Department

38. Laboratory Records (RC)

\section{EXTERNAL DISTRIBUTION}

39. H. M. Henson, TRG Professional Consulting, Inc., Suite 132, 9041 Executive Park Drive, Knoxville, TN 37923.

40. Offics of Scientific and Technical Information, P.O. Box 62, Oak Ridge, TN 37831. 